\title{
Need for moral audit in evaluating quality in health care
}

\author{
Len Doyal
}

Much has recently been written about the importance of clinical audit, a selection of which appeared in the first issue of this journal. The high cost of health care grows in proportion to increasing demand. In Britain the NHS faces an acute crisis of underfunding with little sign of alleviation through increased resources from government or efficiency gained from the new internal markets. Against this background health care must be cost effective with respect to the benefits which patients derive. Clinical audit is to be welcomed to the extent that it aids the achievement of this goal.

The aims and methods of audit, however, have thus far been too narrowly defined. Broadly speaking, they have focused on the extent to which specific types of care have conformed, over given periods, to established patterns of good practice. ${ }^{1}$ A related goal has been the improvement of methodologies to achieve such monitoring and also to assess the costs of different approaches to managing the same medical problems. ${ }^{2}$ Organisational efficiency has also been emphasised, employing management and systems theory to assess units of health care delivery, however narrowly or broadly defined. ${ }^{34}$

These approaches to clinical audit cannot be said to be wrong in themselves. Far from it. They draw welcome attention to the importance of learning from our mistakes in the organisation and management of medicine and of always trying to find ways of improving the principles and practice of health care delivery. Where these perspectives fail, however, is in the narrowness of their interpretation of quality of care itself. ${ }^{5}$ Whether measured in terms of either clinical success or cost-effectiveness, treatment is only one dimension of good health care. Another is the degree to which the moral rights of patients are taken seriously in health care delivery. This paper will argue that without such a moral dimension the process of audit will be seriously incomplete.

St Bartholomew's and The London Hospital Medical Colleges, London

Len Doyal, senior lecturer in medical law and ethics

Correspondence to: Mr L Doyal, Joint Department of Human Science and Medical Ethics, The London Hospita Medical College, Turner Street, London E1 2AD

\section{Why we should take needs and rights} seriously

As individuals our objective welfare depends on the quantity and quality of interaction with others. Through such interaction we discover who we are through learning from others what we can do. Others remind us - as we do them - of the goals which we have tried to achieve in our everyday lives and the degree of success which we have had in the process. They help us to remember what we have done and what we might reasonably try to do in the future.

If we lack the capacity for social participation we are seriously and objectively harmed as a result - disabled with respect to continuing to express ourselves through performing our present skills, learning new ones, and reinforcing others in their attempts to do the same. This applies in the same way to all persons in all cultures. ${ }^{6}$

NEEDS

Identifying significant personal harm with seriously impaired social participation provides the key with which to identify universal and objective human needs. The fulfilment of such needs becomes the necessary condition for avoiding serious harm through being able to participate in society with as little serious impairment as one's genetic or acquired state allows. These conditions - these basic needs - are the personal attributes of physical survival or health and individual autonomy. ${ }^{7}$

As regards the first basic need, without physical survival individuals can clearly do nothing whatever. Reduced physical health hinders the scope of action and interaction with others. The result will be disablement and thus significant harm as defined above. Those ill with severe heart disease or cholera, for example, are objectively more impaired in their social participation than those who are not.

The other basic human need is individual autonomy. In order to participate successfully in any form of life - again, to do anything actors require more than just physical health. They also require the capacity to formulate aims about what to try to achieve and beliefs about how to do so - the ability to reason and to act on the basis of reasons. These attributes create the unique human potential to choose future goals and actions, to plan one's life. Autonomy is the exercise of such reasoned choice and individuals are thus able to participate in their form of life in proportion to their possession of autonomy.

Like physical health, the basic need for

autonomy may be satisfied to a greater or lesser extent. The degree of satisfaction will depend on the value of the three component variables of autonomy: degree of understanding, emotional capacity, and social opportunity. Firstly, individuals must be able to reason appropriately - to know how to attempt to achieve goals deemed to be important and in ways which stand some 
chance of social success. Secondly, individuals who have learnt appropriate manual and mental skills must not be encumbered in their attempts by serious mental illness. Thirdly, the autonomy of individuals will be proportional to the social opportunity to exercise it. The fact that you are physically healthy, educated, and not suffering from severe mental illness will obviously not in itself enable you to participate socially in ways that you choose. ${ }^{7}$

RIGHTS

So much for human needs. The link between them and human rights concerns the inevitability with which we desire others to be good citizens in our terms - to accept and abide by the values with which we identify the moral good. We thus identify good citizens as those who do their moral duty as we think that it should be done.

The imposition of duties of good citizenship upon others entails at least two things on the part of those who impose them. Firstly, they must believe that those on whom these duties are imposed have the right to basic need satisfaction as we have described it. Otherwise they will not be able to do what is expected of them. Remember, it is only to the extent that your basic needs of physical health and individual autonomy are satisfied that you will be able to participate socially at all.

Secondly, the degree to which someone is capable of being a good citizen will in turn depend on the degree of their need satisfaction. Therefore, if we wish for members of society to be very good citizens in our terms then we must support their right to the high levels of need satisfaction required for them to be so. To do otherwise would be morally inconsistent in that we cannot profess belief in some vision of the good and not accept that all others should be able to do their best to embrace it. ${ }^{8}$

Moral incompleteness of orthodox audit

There is now a professional consensus about the moral and legal duties of clinical care: to protect life and health and to respect autonomy to an acceptable standard. ${ }^{9}$ Orthodox audit focuses on the former. Yet the importance for health care of both sets of duties follows from the preceding arguments.

From the perspective of their own moral commitments all clinicians believe that both they and their patients have certain duties. One of these is to be a good patient - once the choice has been made to have medical treatment, to act responsibly through doing one's best to follow whatever plan of medical management that has been prescribed. Yet for such beliefs to be consistent - for good compliance to be a practical proposition - all patients must have the physical but also the emotional, intellectual, and social competence to choose to act accordingly. To deny some this opportunity while expecting them still to be good citizens and good patients would be both inconsistent and unjust.

But this is just to restate the duty of clinicians to do their best to optimise both the physical health and the autonomy of their patients in ways which are not arbitrary and prejudicial. Given this argument, it should be clear how much is morally missing from orthodox clinical audit if it neglects the success to which these principles of autonomy and justice are being fulfilled. Just to focus on the success of therapeutic intervention would be compatible with the possibility of accepting that all was well with the quality of care in a colony of slaves!

When respect for individual autonomy is translated into a clinical setting it reduces to respect for three subsidiary rights: to informed consent, to be told the truth, and to have confidentiality respected. ${ }^{10}$ Let us first, therefore, attempt to assess - albeit impressionistically - how far these principles are reflected in clinical practice. We will then ask the same type of question about the presence of arbitrary injustices in the distribution of clinical resources for patients.

\section{CONSENT}

In fact, we know very little about the quality of informed consent in clinical practice in the United Kingdom. Yet there is good reason to be pessimistic. No systematic instruction is given about either principle or practice in most medical colleges. This violates explicit dictates of the General Medical Council and is part of the background to frequent complaints among junior doctors about their professed incompetence to obtain proper consent. ${ }^{11}$ Few empirical investigations have been done to assess what patients have been told about clinical interventions or how much they actually understand about what they have been told, or both. ${ }^{12}$

The new consent forms recently issued by the Department of Health only add to the confusion. ${ }^{13}$ They still do not provide clear instructions for gaining properly informed consent to treatment or the space to record the information required for this purpose. Even systematic information about their use would be of little help in evaluating the degree to which the right to informed consent was being respected in practice. In primary care the situation is even more problematic since most consent is implied rather embodied in a signed consent form. Here there seems to be no monitoring at all.

But informed consent to clinical intervention is only part of the story. Proper consent to treatment also entails consenting to the environment within which the treatment is administered. In order to do this the patient needs adequate information about relevant institutional rules and procedures. For example, it seems a commonplace within many teaching hospitals that patients commonly do not understand the circumstances in which they can refuse to be seen by students. Literature outlining their rights is often made available to patients (though not always!). However, we don't know how accurate it is, and whether or not the moral principles it embodies can be defended or if and when they are actually put into practice. 
TRUTHFUL COMMUNICATION

It is now commonly accepted that the bad old days of crude paternalism in medicine are mostly over. In the past outright lies about prognosis or hazardous side effects of therapeutic interventions were often justified as being in the best interests of the patient. Yet young doctors and nurses still complain that the right of patients to the truth is often compromised with justifications of this kind lurking in the background. Poor communication can have the same consequence as outright dishonesty, with patients not receiving information which they require to make significant life choices.

On the face of it the few indicators of current practice which do exist are not encouraging. A significant proportion of patients who activate formal complaints procedures focus on the belief that inaccurate or incomplete information has been provided and that clinicians have not been honest in admitting it. ${ }^{14}$ Junior doctors complain about the confusion created by different consultants on the same firm having different policies about what patients should be told. ${ }^{15}$ Nurses complain about having to "pick up the pieces" for doctors who cannot or will not face giving their patients adequate information.

We simply don't know how often these complaints are made or to what extent they are justified. Given the disastrous consequences which deceptions can entail for some patients, the urgency of proper audit to find out cannot be overestimated.

CONFIDENTIALITY

Confidentiality is commonly believed to be a right of patients which is taken seriously. The devastating consequences of breaches of confidence for the relationship of trust so crucial to clinical success are well known and accepted. Equally, the immense attention shown to confidentiality in sensitive areas like HIV infection and in vitro fertilisation, along with the lack of public outcry about abuses, suggests that here at least all is well.

Unfortunately, good patterns of practice cannot necessarily be inferred from lack of complaint. Once we move away from those areas where patients would be most likely to protest to those where they may well feel constrained not to do so, we are left yet again with little more than impressions. ${ }^{16}$

And the impressions differ. A commonplace among health professionals is that confidentiality is almost impossible on a Nightingale ward. Individual cases are discussed within earshot of other patients, often with little or no attempt to address the moral issues of so doing. Clinical rounds are enough of a problem in this respect. Teaching rounds can become nightmarish, with clinical tutors sometimes having almost to shout the clinical details of patients to sometimes quite large groups of students standing around them, desperately trying to hear.

To be sure, respect for confidentiality differs widely within teaching and clinical practice, but we do not know how much. And again, because patients by and large do not protest they may well not regard such circumstances as a violation of their rights but as an unavoidable consequence of reaping the advantages of the NHS. But because the research has not been done, we again don't know.

This ignorance is compounded when we turn to the other serious issue concerning confidentiality in secondary care - what is and is not told to patients' relatives. Breaches of confidence almost certainly occur daily in a wide variety of communications with relatives. Though health professionals generally understand the importance of respecting confidentiality, there are immense pressures to do otherwise for reasons which often seem to be in the best interests of both patients and their relatives.

As regards patients, personal information is sometimes needed for their care which they are unable to give, and an exchange of general information with relatives about condition, treatment, and prognosis can seem a reasonable price to pay. As for relatives, when they are confused and distressed it is tempting to provide some relief through providing similar information. Under these circumstances the quality and quantity of confidential information which is released varies enormously, depending on the pressures exerted by relatives and the communication skills of staff and their understanding of the moral issues.

Such pressures should be resisted and often are, in highly sensitive and creative ways, through providing very general and vague information which does not breach confidence. Yet this is not always successful, with devastating potential consequences for both patient and relative. Patients may have choices foreclosed which they wish to make sometimes in attempts to avoid exploitation by the very relatives concerned. Relatives risk the distress of discovering a poor prognosis which they may not have been expecting and about which the patient may have wished to inform them personally.

The problems extend further when we consider dilemmas posed by the medical records, their computerisation, and the fact that much communication about patients takes place in telephone calls. ${ }^{17}$ Given the importance attached to confidentiality within the profession, it is extraordinary that we have so little documented information about patterns of good and bad practice within our hospitals. Clearly, we can only discover and learn from such patterns through looking for them in properly conducted empirical research.

\section{JUSTICE}

As suggested earlier there is a sense in which it would be possible to envisage a good quality of care - narrowly construed in reductionistic terms - in a colony of slaves. To extricate ourselves from this paradox we have now expanded the concept of quality of care to include the duty to respect the autonomy of 
patients: their right to determine their own medical destiny. Yet we are still not quite out of the wood.

Suppose we have implemented programmes of research to monitor success in protecting life and health and respecting autonomy. Unless the auditing process includes an evaluation of the degree to which both are equally distributed throughout the patient population, it will still be morally incomplete. The needs and rights of some patients might well be taken more seriously than others and for reasons which are prejudicial or based on vested interests.

One of the hallmarks of our political system - and certainly of the NHS - is that it is the common humanity of individuals which generates their right to be treated as moral equals. Our preceding argument about the close link between basic needs, expectations of good citizenship, and rights underlines the logical inconsistency of thinking otherwise. Remember, if clinicians wish all patients to do their best to be good patients then they must in return do their best to satisfy the basic needs which will enable them to do so. Of course different patients will require unequal degrees of effort, depending on their existing levels of physical health and autonomy. Yet this fact in no way negates their equal right to the best care available to achieve both ends.

Again, this principle of equality goes to the very heart of the moral foundation of the health service - access based on need and not ability to pay. In practice, however, we know little about the degree to which practice within the service conforms to the ideal.

As regards the protection of physical health, audit procedures should detect arbitrary patterns of clinical care where they exist. ${ }^{18} 19$ For example, individual clinicians might consciously or unconsciously prescribe treatment in ways which are based on factors other than clinical advisability per se (for example, age, sex, race, or sexual preference). If such patterns of discrimination are revealed the question of equity reduces to what then happens to correct the situation. It is hopefully the case that such patterns of discriminatory care are rare. However, without further research, we cannot say.

The same applies to other aspects of health care delivery. Patients sometimes complain about perceived discriminatory practice in various contexts - processing in reception, treatment by nursing staff, communication in outpatients - the list goes on and the argument for more systematic research grows stronger. $^{2021}$

So much for our ignorance of possible injustice as regards the provision of care. The same issues of justice emerge within debates about the micro-allocation and macroallocation of resources on both purchasing and providing sides of the internal market. It follows from the principle of equal access to health care on the basis of need that a just health service must include a broad range of basic medical services approximating to that which is currently in place. To do otherwise would be to penalise arbitrarily those who just happen to suffer from some diseases rather than others. Therefore when rationing becomes inevitable, as will always be the case for some treatments and patients, it can be justified only within the provision of treatments but not between them. ${ }^{10}$

If properly administered on the provider side, waiting lists constitute a rational and effective way for micro-rationing to occur. As long as each patient is deemed to possess roughly the same level of clinical need then his or her place on the waiting list should be based only on the time at which they contracted their illness. Their place on the list is randomised, so to speak, by the lottery of life. How clinical need is to be deemed morally similar for the purposes of such randomisation is beyond the scope of this paper. Suffice it to say that there will come a point when clinical need will be so different, prognosis so poor, and age so great that these variables will have to be taken into account in deciding who gets what. ${ }^{10}$

The moral complexity of associated arguments, however, does nothing to obviate the importance of collecting information about the fairness with which waiting lists are currently administered, including the criteria which are used to prioritise patients who have been on the lists for less time than others. Given the competing perceptions of clinical need by those who in turn compete for space on the lists on behalf of their patients, there is ample room for prejudice and vested interests to creep into the picture. The same argument applies to the criteria which determine the removal of patients from the lists altogether. Little research has been done to evaluate inequity in these micro-levels of allocation. ${ }^{22}$

The situation is just as bad as regards our understanding of the processes of macroallocation on the purchasing side. At present, block contracts are based on crude approximations of need that often amount to little more than assuming a steady state as regards past expenditure. Attempts are only just beginning to assess the reliability of these estimates or to articulate the conceptual and methodological criteria on which they are based.

The size and specification of contracts can be further distorted by traditional biases towards expenditure on some areas of care at the expense of others, prejudices which sometimes remain unacknowledged or defended in any public forum. Notoriously, the award of extracontractual referrals is currently riddled with intuitive decision making, equally subject to arbitrariness and inequity.

So far, we have criticised the extremely limited procedures available for auditing the priority given to patients' rights. There is much impressionistic evidence to suggest that these rights are not audited. Of course, we should and do operate on the assumption that professionals do their best against the background of accepted values about what "best" amounts to. Yet the fact remains that we do not really know how these values are 
generally perceived and translated into consistent patterns of clinical practice. Therefore in evaluating the quality of health care delivery the concept of "quality" must expand to include all of the basic needs and rights of patients as people. Medical audit, in short, must include moral audit.

\section{Moral audit: the way forward}

Clearly, it is one thing to argue that any evaluation of the success of clinical care should include an assessment of success in respecting the autonomy of patients or the justice of the delivery of such care. It is another thing entirely to know where to begin. The difficulties are twofold.

Firstly, there is a general consensus about what respect for the autonomy of patients should mean in principle. However, this is insufficient itself to guide the empirical research required for effective monitoring. What is required is for purchasers and providers to work together to create more detailed guidelines of good practice for obtaining informed consent, truthful communication, maintaining confidentiality, and fairly distributing appropriate health care on a micro- and macro-basis. Secondly, there is nothing analogous to already existing medical records employed in current clinical audit. In most cases data about whether or not health professionals are conforming to good moral and legal practice; however specifically defined, will have to be collected ab initio.

\section{GUIDELINES FOR MORAL AND LEGAL GOOD} PRACTICE

So the creation of guidelines of good practice is where the evolution of moral audit should begin. Only then will we know what data to collect, for only then will we understand what we are looking for. The creation of such guidelines entails two types of research. On the one hand principles must be formulated which reflect the best available understanding of the ethical and legal principles and arguments which surround the issue at hand. On the other, these principles must be translated into simple procedural codes which are discussed with representatives of all staff involved in relevant decision making, as well as with representatives of patients. ${ }^{23}$ This will ensure as much as possible their conformity with what is already perceived as good practice, along with their general feasibility for future practice.

For example, there has been much recent discussion of "not for resuscitation" orders and the extent to which they conform to acceptable moral principles concerning informed consent. The pattern of research advocated here would therefore begin with discussion among the preceding groups of the moral and legal principles to which such codes should adhere, followed by the creation of a hypothetical set of resuscitation guidelines, the distribution of these guidelines to all relevant staff for critical feedback, and the formal incorporation of the resulting final version into hospital or trust policy. A version of this procedure has already begun - for example, at the Royal London Hospital.

The same procedures could be adopted to articulate guidelines of good practice concerning all the dimensions of patients' rights discussed above. Thus with informed consent we must decide what and how patients should be told about their illness, proposed treatment, alternatives, prognosis, hazards, and so on. Further decisions will have to be made about appropriate ways of recording the fact that this information has been truthfully communicated. As for confidentiality, guidelines would stipulate who was entitled to what categories of information and under what circumstances. Such clarification would particularly apply to constraints on communicating with self announced relatives and close friends. Concerning justice, purchasers would have to clarify the bases on which they allocated resources, along with the moral justification for doing so. Again, all such documentation should be published after wide consultation, distributed to those in relevant practice, and be a matter of public record.

\section{RESEARCHING CONFORMITY TO SUCH} GUIDELINES

When guidelines of the preceding kinds are in place the process of moral audit can begin systematically. It will have already started to a degree through consultations involved in the creation and finalisation of the guidelines themselves. Much will be learnt in the process about the degree to which rights and justice are already reflected in patterns of provision and purchasing. Yet almost all of this information will be unsystematic both in its collection and in its reliability. What will then be required is systematic research attempting to confirm the degree to which future practice conforms to guidelines when they become "official."

Such research could either be done in its own right or in tandem with already existing procedures of clinical audit. Again, official guidelines would become hypotheses continuously under test in much the same way that good standards of clinical practice are now supposed to be. As regards some problems, for example, the degree to which surgical patients had been properly informed about the risks of different sorts of interventions, such research might focus, say, on the contents of clinical notes and signed (and further improved) consent forms.

Other problems - say, the degree to which patients believe that they were being given sufficient information about their illnesses or treatments or that their privacy was being illegitimately invaded - would be explored through questionnaire research. Similar methodologies apply to the assessment of equity throughout provision and purchasing practice. Once purchasers have developed clear policies about how waiting lists should be managed, the discovery of whether or not practice conforms to principle will not pose significant methodological problems. 
Finally, however, the major difficulties which must be overcome are the willingness of staff to take moral audit seriously and the financial costs of implementing it against the background of existing shortages of resources. As regards staff, there is little reason for pessimism, provided that the demand for moral audit is placed on the same footing by purchasers in contracts for quality as that for clinical audit (for some related ideas see reference 24). Equally, audit must occur according to current good practice concerning confidentiality and rational debate, in which no one is criticised for not conforming to standards about which they had little or no understanding or professional guidance.

Against the background of what is often appalling education in ethics and law, the focus of moral audit should be on learning from our mistakes rather than professional retribution unless the pattern of error reflects sustained negligence. Recall that moral audit of the kind envisaged would occur only after guidelines of good practice had been adopted with the advice of the health professionals then audited.

Concerning finance, we face more difficult dilemmas. There is no question but that the creation of programmes of moral audit of the kind envisaged would entail significant expenditure. Ideally, research staff employed with this as their brief should become part of the formal arrangements for clinical audit in all provider units, paid for by purchasers. This will entail access to appropriate capital equipment and other relevant research facilities. More problematically though, it will also entail relevant expertise in analysing ethical and legal issues surrounding health care.

Since there are still far too few centres and courses where such training occurs the expansion of these should be seen as an important condition for the success of the proposals which have been outlined. It also follows that we need to increase the time devoted to teaching and formally assessing ethics and law in the new clinical and nursing curricula which are now being developed for the 1990 s and beyond. ${ }^{25}$ If the government in the United Kingdom takes seriously its own rhetoric concerning patients' rights it will recognise its moral responsibility to make funding available for the success of these initiatives.

\section{Conclusion}

This paper has argued that the domain of clinical audit must be expanded to evaluate the degree to which the autonomy of patients is respected and health care resources are justly allocated. Both types of inquiry will depend on the formulation of moral and legal guidelines for good practice and ongoing research to monitor the conformity of practice with principle. This might occur independently or alongside existing procedures for clinical audit. Funding should be made available for moral audit by a government which proclaims its interest in patients' rights.

Much is at risk if these proposals for the future of audit are not adopted. One of the best ways to protect the NHS is to nourish the unique moral texture of the clinical relations within it. The advantages of doing so namely, strong feelings of moral reciprocity often foreign to professional relationships based primarily on commercial contact - will only be sustained if the rights of patients are taken seriously. They increasingly expect and demand it. As health professionals we should expect it of ourselves and monitor our professional activities accordingly.

I thank Lesley Doyal and Ian Jones for their help and advice.

1 Russell IT, Wilson BJ. Audit: the third clinical science? Quality in Health Care 1992;1:51-5.

2 Donabedian A. The quality of care. $\mathcal{F} A M A$ 1988;260:1743-8.

3 Berwick DM, Enthoven A, Bunker JP. Quality management in the NHS: the doctor's role. I. $B M \mathcal{F}$ 1992;304:235-9.

4 Berwick DM, Enthoven A, Bunker JP. Quality management in the NHS: the doctor's role. II. BMF 1992;304:304-8.

5 Pfeffer N, Coote A. Is quality good for you? London: Institute For Public Policy Research, 1991:34-6.

6 Doyal L, Gough I. $A$ theory of human need. London: Macmillan, 1991:50-2.

7 Doyal L, Gough I. $A$ theory of human need. London: Macmillan, 1991:49-69; 171-87.

8 Doyal L, Gough I. $A$ theory of human need. London: Macmillan, 1992:91-115.

9 British Medical Association. Philosophy and practice of medical ethics. London: BMA 1988.

10 Doyal L. Needs, rights and the moral duties of clinicians. In: Gillon R, ed. Principles of health care ethics. London: Wiley (in press).

11 Dowling S, Barrett S. Doctors in the making. Bristol: University of Bristol, 1991:15.

12 Davies H, Fallowfield L. Counselling and communication in health care. In: Counselling and communication in health care. London: Wiley, 1991:12.

13 NHS Management Executive. A guide to consent for examination to treatment. London: Department of Health, 1990.

14 Dickson D, Hargie O, Marrow N. Communication skill training for health professionals. London: Chapman and Hall, 1989.

15 Dowling S, Barrett S. Doctors in the making. Bristol: University of Bristol, 1991:82-6.

16 Ley P. Communicating with patients: improving communication, satisfaction, and compliance. London: Croom Helm, 1988.

17 Siegler M. Confidentiality: a decrepit concept? $N$ Engl $\mathcal{f}$ Med 1982;307:1518-21. 18 Maxwell RJ. Quality assessment in health. BMf

19 Donabedian A. The seven pillars of quality. Archives of Pathology and Laboratory Medicine 1990;114:1115-8.

20 Todd A. Intimate adversaries: cultural conflict between doctors and women patients. Philadelphia: University of Pennsylvania Press, 1989.

21 Littlewood R, Lipsedge M. Aliens and alienists: ethnic minorities and psychiatry. Harmondsworth: Penguin, 1982.

22 Kilner J. Who lives? Who dies? New Haven: Yale University Press, 1990.

23 Hughes J, Humphrey C. Medical audit in general practice: a practical guide to the literature. London: King's Fund, 1990:41-2.

24 Hopkins A, Maxwell R. Contracts and quality of care. BMF 1990;300:919-22.

25 General Medical Council. Recommendations on general clinical training. London: GMC, 1992. 